\title{
Role of the Insulin-Like Growth Factor Type 1 Receptor in the Pathogenesis of Diabetic Encephalopathy
}

\author{
Duo Zhang, ${ }^{1}$ Shuang Jiang, ${ }^{2}$ and Heng Meng ${ }^{1}$ \\ ${ }^{1}$ Department of Radiology, Affiliated Hospital of BeiHua University, JiLin 132011, China \\ ${ }^{2}$ College of Basic Medical Sciences, Changchun University of Chinese Medicine, Changchun, Jilin 130117, China \\ Correspondence should be addressed to Heng Meng; heng.meng0432@gmail.com
}

Received 29 June 2014; Accepted 9 September 2014

Academic Editor: Ilias Migdalis

Copyright (c) 2015 Duo Zhang et al. This is an open access article distributed under the Creative Commons Attribution License, which permits unrestricted use, distribution, and reproduction in any medium, provided the original work is properly cited.

\begin{abstract}
Defective cognitive function is common in patients with diabetes, suggesting that insulin normally exerts anabolic actions in neuron, namely, diabetic encephalopathy. However, because insulin can cross-activate the insulin-like growth factor type 1 receptor (IGF-1R), which also functions in most of tissues, such as muscle and bone, it has been difficult to establish the direct (IGF-1independent) actions of insulin in the pathogenesis of diabetic encephalopathy. To overcome this problem, we examined insulin signaling and action in primary PC-12 cells engineered for conditional disruption of the IGF-1 receptor $(\Delta \mathrm{IGF}-1 \mathrm{R})$. The results showed that the lower glucose metabolism and high expression of IGF-1R occurred in the brain of the DE rat model. The results also showed the defect of IGF-1R could significantly improve the ability of glucose consumption and enhance sensitivity to insulininduced IR and Akt phosphorylation in PC12 cells. And meanwhile, IGF-1R allele gene knockout (IGF-1R ${ }^{\text {neo }}$ ) mice treated with HFD/STZ had better cognitive abilities than those of wild mice. Those results indicate that insulin exerts direct anabolic actions in neuron-like cells by activation of its cognate receptor and prove that IGF-1R plays an important role in the pathogenesis of diabetic encephalopathy.
\end{abstract}

\section{Introduction}

The case reports are presented in the order of increasing severity of the neuropathological changes $[1,2]$. The severe damage found on histological examination of the brains from the patients justifies the term encephalopathy [3-5]. One point of interest was whether cerebral changes were the cause or a sequela of the disease $[6,7]$. Diabetes and its treatment are associated with functional and structural disturbances in the brain [8-10]. Many existing publications focused on changes in cerebral function and structure that develop more insidiously [10]. These changes are referred to as diabetic encephalopathy (DE), a term that encompasses functional impairment of cognition, cerebral signal conduction, neurotransmission and synaptic plasticity, and underlying structural pathology associated with diabetes [11-14].

Insulin-like growth factor-1 (IGF-1) that is a single-chain polypeptide is widely expressed in central nervous system [15-17]. Overexpression and genetic ablation of components of the IGF system in animal models can lead to developmental anomalies and functional disturbances [18-20]. IGF-1 acts primarily through its receptor, IGF-1 receptor (IGF-1R), which is widely distributed in the brain [21]. Binding of IGF-1 to IGF-1R may activate two major signaling pathways, PI3K/Akt and MAPK pathways [22-24]. The activated form of Akt, phosphorylated Akt (p-Akt), may inhibit several proapoptotic factors including glycogen synthase kinase-3 beta (GSK-3 beta), fork-head homolog in rhabdomyosarcoma (FKHR), Bcl-2-associated death protein, and caspase-9; each of them may influence neuronal survival after stroke [25]. Autophosphorylation increases the kinase activity of IRtype receptors by 3 orders of magnitude, enabling them to phosphorylate a number of substrate proteins and engender growth or metabolic responses $[26,27]$. In addition to forming homodimers, IR and IGF-1R can form heterodimers with each other [28-30].

To examine the direct actions of insulin in diabetic encephalopathy (DE) and elucidate signaling pathways downstream of the IR, we used a model for conditional removal of the IGF-1R in vitro by adenoviral introduction 
of the Cre-recombinase to primary rat PC-12 cell derived from mice carrying floxed IGF-1R alleles. We show that PC-12 cells lacking the IGF-1R are two to three times more sensitive to insulin than are cells expressing both receptors. And in the model for downregulated IGF-1R in vivo, the knockdown (IGF-1R ${ }^{\text {neo }}$ ) mice treated with HFD/STZ have better cognitive abilities than those of wild mice. It is concluded that insulin exerts direct anabolic actions in neuron-like cells by activation of its cognate receptor; the solid data provided in the study proves that IGF-1R plays an important role of in the pathogenesis of DE.

\section{Materials and Methods}

2.1. Experimental Animals and Creation of Animal Model. Wistar rats (male, weighing 180-200 g) were supplied by the Laboratory Animal Center of BeiJing. All animal experiments were conducted according to the guidelines of the local animal use and care committees and executed according to the National Animal Law. The animals were divided into three groups: normal controls (CON, $n=25$ ), diabetic encephalopathy ( $\mathrm{D}, n=25)$, and diabetic encephalopathy (DE, $n=25)$. The rats were fed with HFD for 4 weeks; STZ was prepared before each use at $20 \mathrm{mg} / \mathrm{mL}$ in $0.1 \mathrm{M} \mathrm{pH} 4.4$ citrate buffer and was injected at $150 \mathrm{mg} / \mathrm{kg}$, i.p., into rats which had been fasted for $12 \mathrm{~h}$ prior to receiving the injection. Four days later, nonfasting blood glucose in a tail-vein sample was determined by a glucose analyzer; a value $>15 \mathrm{mM} / \mathrm{L}$ was accepted as a successfully created diabetic model.

The IGF receptor null (IGF-1R ${ }^{-}$) mice were not used in this study, because Epaud et al. reported that IGF-1R ${ }^{-/-}$ embryos displayed severe lung hypoplasia and markedly underdeveloped diaphragms, leading to lethal neonatal respiratory distress [30]. IGF-1R allele gene knockout (IGF-1R ${ }^{\text {neo }}$ ) mice described previously $[6,13,21]$. For studies in young adult mice, IGF-1R ${ }^{\text {neo }}$ mice were 9 to 12 weeks old. Mice lived under SPF conditions in individually ventilated filter-cages. All IGF- $1 \mathrm{R}^{\text {neo }}$ mice were provided by Changchun ibiocc Co., Ltd. Preparation of HFD/STZ-induced diabetic mice refers to the publication [31].

2.2. Test of Abilities of Learning and Memory. Morris water maze tests were performed after training for 12 weeks. After the rats were familiar with the testing environment, normal training was performed from the second day. Orientation test: rats were trained twice per day, one time in the morning and one time in the afternoon. Each training lasted for $120 \mathrm{~s}$ and the gap time was $30 \mathrm{~s}$. This training lasted for 4 days. Starting area was randomly selected and the number of times rats touch the platform in $120 \mathrm{~s}$ was recorded. The platform was removed, and the rats were put into water at the opposite side of the platform. The percent of residence time in the center area and number of times of passing the former platform in $120 \mathrm{~s}$ were recorded.

2.3. In Vivo PET Studies. PET studies were performed in the rats which were suffering from diabetes or diabetic encephalopathy ( $n=20$ per group). The PET protocol was the following report.

2.4. Biochemistry Markers Test. The brains of rats in each group after the test of abilities of learning and memory were collected on the ice and then the hippocampus was dissected. Tissues were crushed and centrifuged at the speed of $2000 \mathrm{r} / \mathrm{min}$ for $10 \mathrm{~min}$. The supernate was collected and the activities of SOD, GSH-Px, CAT, and content of MDA in the rat hippocampal gyrus were detected. Coomassie brilliant blue staining was used to detect protein concentration.

2.5. HE Staining Test. Thirty $\mu \mathrm{m}$ brain coronal sections were collected from every $200 \mu \mathrm{m}$. The sections were deparaffinized, with two changes of xylene, $10 \mathrm{~min}$ each. They were rehydrated in 2 changes of absolute alcohol, for 5 min each, $95 \%$ alcohol for $2 \mathrm{~min}$ and $70 \%$ alcohol for $2 \mathrm{~min}$, then washed briefly in distilled water, and stained in Harris hematoxylin solution for $8 \mathrm{~min}$. They were washed in running tap water for $5 \mathrm{~min}$ and differentiated in $1 \%$ acid alcohol for $30 \mathrm{~s}$. After this, they were washed in running tap water for $1 \mathrm{~min}$ and blued in $0.2 \%$ ammonia water or saturated lithium carbonate solution for 30 to $60 \mathrm{~s}$. Again they were washed in running tap water for $5 \mathrm{~min}$, rinsed in 95\% alcohol, at 10 dips, and then counterstained in eosin-phloxine solution for $30 \mathrm{~s}$. They were dehydrated in 95\% alcohol, 2 changes of absolute alcohol, $5 \mathrm{~min}$ each. They were cleared in 2 changes of xylene, 5 min each, and mounted with xylene based mounting medium. The neurons in CA1 in hippocampus were observed using optical microscope.

2.6. IHC Staining Test. After dissecting tissues at $5 \mu \mathrm{m}$ and fixing them in $4 \%$ paraformaldehyde for $10 \mathrm{~m}$, slides were incubated 2 to 3 times in xylene for $10 \mathrm{~m}$ each and then incubated twice in $100 \%$ ethanol for $2 \mathrm{~m}$ each. They were hydrated by placing in 95, 70,50, and 30\% ethanol for $2 \mathrm{~min}$ each. Slides were placed into buffer containing 5\% normal goat serum for $10 \mathrm{~min}$. Slides were incubated in a humidified chamber overnight with primary antibody (rabbit anti-rat Akt/PKB 1:500, rabbit anti-rat GLUT4 1:1000). They were washed in $5 \mathrm{~m}$ in buffer for 3 times and incubated with secondary antibody in a humidified chamber for $30 \mathrm{~min}$. DAB and hematoxylin staining, 5 discontinue brain sections were selected and 5 fields were selected randomly. The numbers of Akt/PKB and GLUT4 positive cells in CA1 were counted.

2.7. Western Blot. Run $20 \mu \mathrm{g}$ protein per lane after heating at $100^{\circ} \mathrm{C}$ for $5 \mathrm{~min}$. Run on an SDS-PAGE gel until the blue front is at the bottom of the gel. Transfer to a nitrocellulose membrane for $0.5 \mathrm{~A}-\mathrm{h}$. Block the membrane for $1 \mathrm{~h}$ in $5 \%$ nonfat dry milk in $1 \times$ PBST, in a small Tupperware dish on a shaker. Incubate with primary antibody (rabbit anti-rat pAKT 1:500, rabbit anti-rat GLUT4 1:1000, and rabbit antirat $\beta$-actin $1: 200)$ at $4^{\circ} \mathrm{C}$ overnight. Wash 3 times for 5 to $10 \mathrm{~min}$ in $50 \mathrm{~mL} 1 \times \mathrm{PBS}$ with $0.1 \%$ Tween 20 at RT. Incubate with goat anti-rabbit $1: 200$ for $1 \mathrm{~h}$ at RT in $1 \times \mathrm{PBST}$, wash $3 \times$ $10 \mathrm{~min}$, and rinse with $\mathrm{ddH}_{2} \mathrm{O}$. Detect protein with ECL kit ( $2 \mathrm{~mL} / \mathrm{membrane})$. In a separate tube, mix black and white 


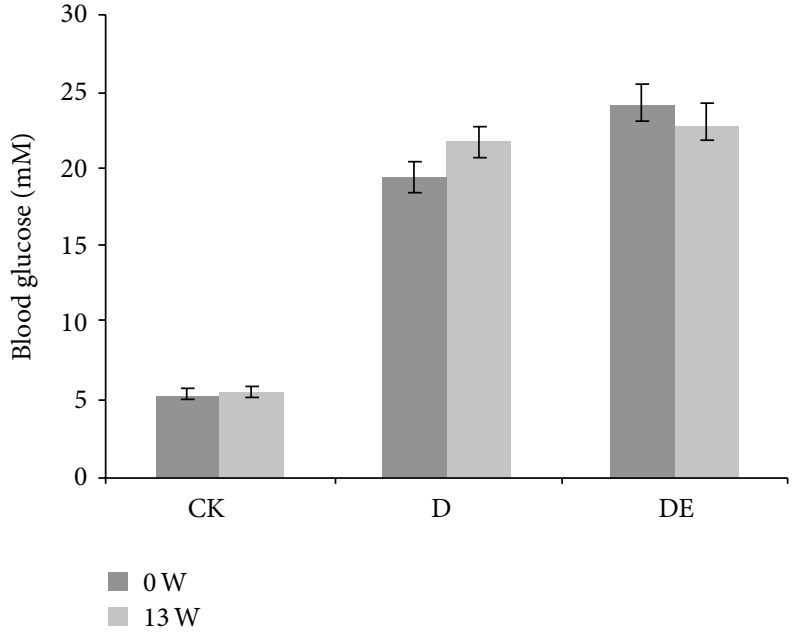

(a)

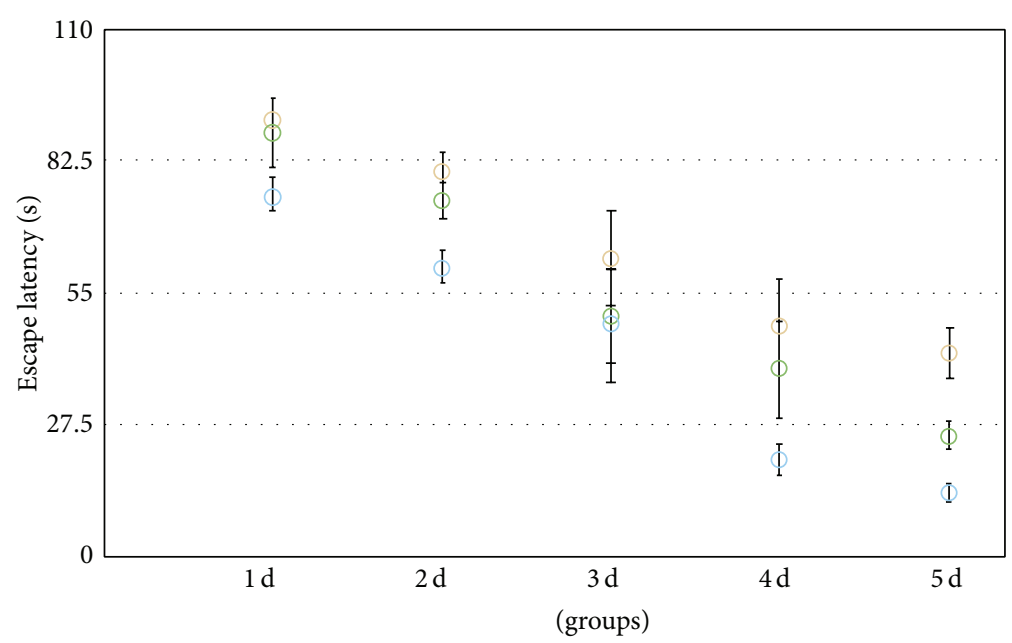

(c)

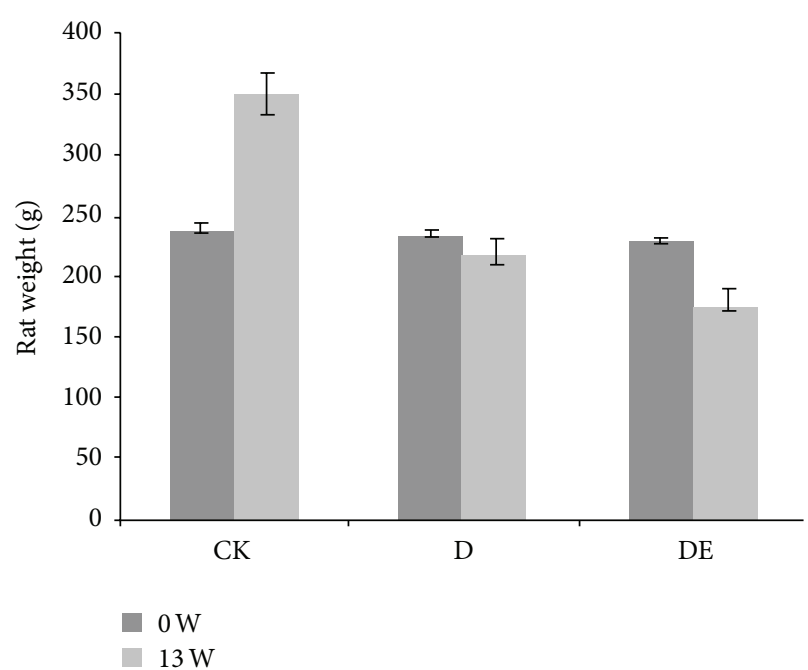

(b)

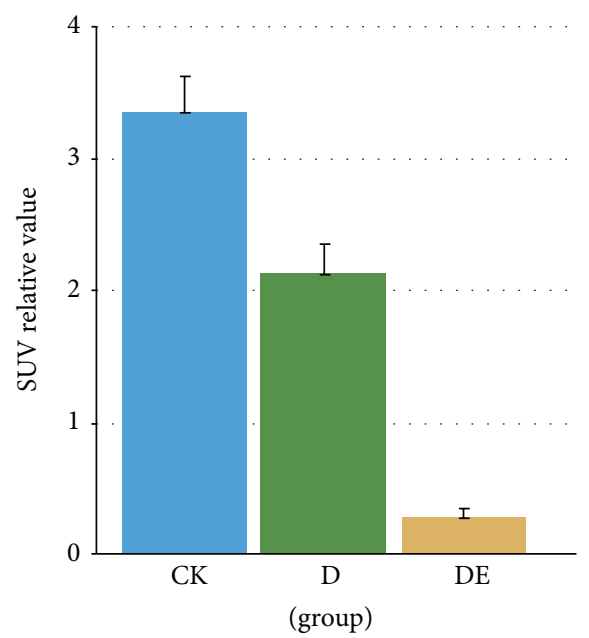

(d)

Figure 1: Blood glucose (a) and body weight (b) of mice in 3 groups. The ability analysis of learning and memory of mice in 3 groups (c). Evaluation of brain glycometabolism in DE animals by PET/CT $(d)$.

ECL solutions in a 1:1 ratio. Then add aliquot solution onto membranes and wait for $1 \mathrm{~min}$. Drain the ECL, wrap in plastic, and expose to film. The value of protein would be compared with $\beta$-actin, and the relative potency ratio would stand for the expression of protein.

2.8. Statistical Analysis. Data were expressed as mean \pm standard deviation $(M \pm S D)$. Group differences in the swimming time in the Morris water maze test and the number of errors in the passageway water maze test were analyzed by SPSS 11.0 using Windows software to conduct two-way analysis of variance (ANOVA, equal variances assumed by S-N-K) on repeated measurements. Other data were analyzed by SPSS 11.0 using Windows software to conduct one-way ANOVA (equal variances assumed by $\mathrm{S}-\mathrm{N}-\mathrm{K}$ ). A post hoc test was used to obtain the $P$ values. $P<0.05$ was considered significant.

\section{Results}

3.1. Comparation of Study and Memory Ability. The rats of $\mathrm{D}$ group and $\mathrm{D}+\mathrm{DE}$ were with polydipsia, polyphagia, polyuria and weight loss, yellowish color, and poor spirit of the late, slow-moving symptoms. As shown in Figure 1, at the beginning of generating animal model, the values of blood glucose in $\mathrm{D}$ group and $\mathrm{DE}$ groups were much higher than Normal Control group in the 13th week $(P<0.01)$; the body weight of mice in 3 groups showed the same situation $(P<0.01)$.

During the training period, the escape latency in all rats decreased significantly as training days increased (F day $=$ 1324.66, $P<0.01)$. To use the Morris water maze test, the rats in DE group had more swimming time than that in $\mathrm{D}$ group $(P<0.05)$ and made significantly more errors compared with that of Normal Control group $(P<0.05)$. The rats showed reversed behavioral alternation with levels returning close to that of rats in the control group (Figure 1(c)). 


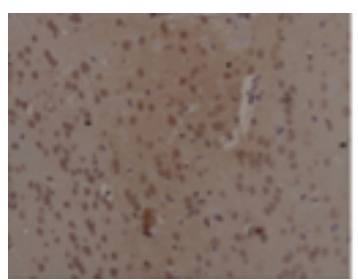

DE

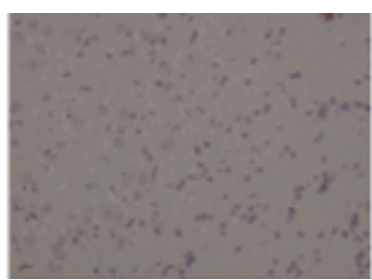

D

(a)

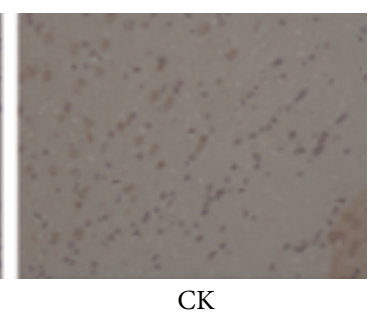

CK

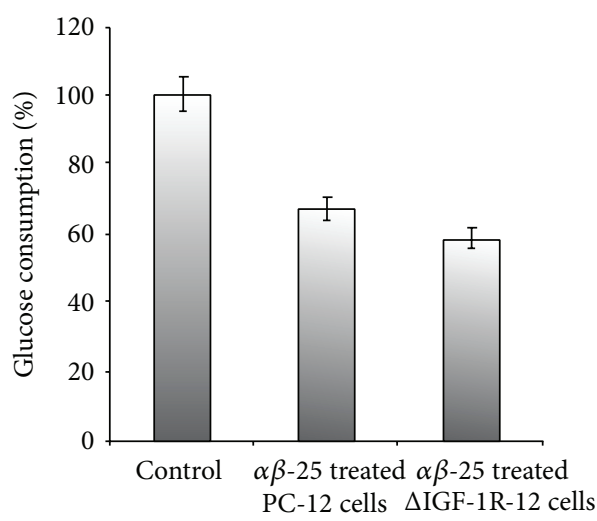

(c)

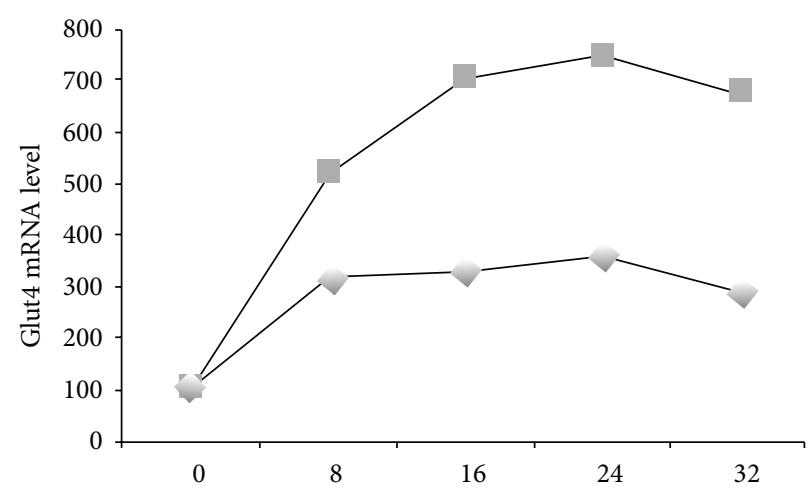

(h)

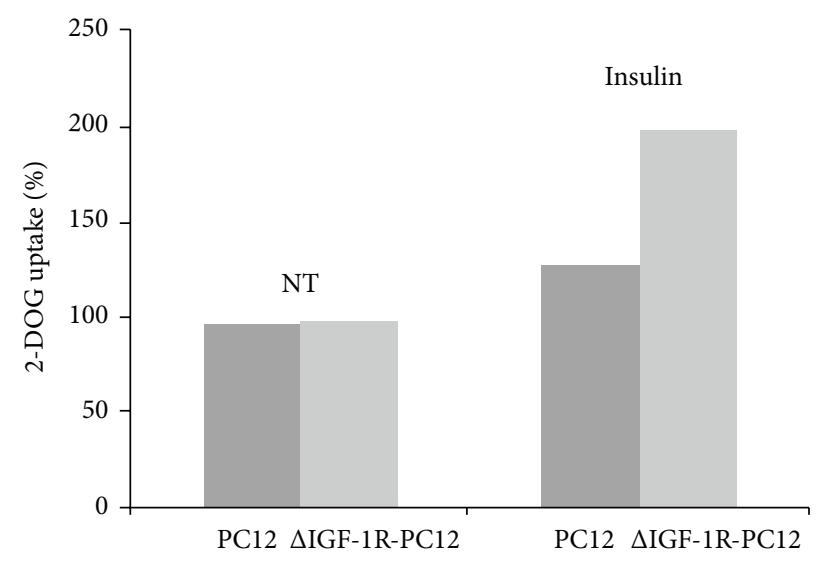

$-\checkmark$ NC

-- IGF

(d)

(e)

FIGURE 2: Expression of enhanced IGF-1R (a) and IR (b) in the hippocampal gyrus of DE rats. Enhanced insulin-induced glucose transport in $\triangle$ IGF-1R PC-12 cells (c, d, and e).

3.2. The Lower Glucose Metabolism in the Brain of the DE Rat Model. To investigate glucose metabolism in the DE rat model, the changes of $\left[{ }^{18} \mathrm{~F}\right]$-FDG-PET images were recorded. A significant positive correlation was found between $\mathrm{D}$ group and DE group and the $\left[{ }^{18} \mathrm{~F}\right]-\mathrm{FDG}$ uptake in the cortex and the hippocampus. Evaluation of glucose metabolism in animals revealed a decrease of cortical and hippocampal glucose uptake in the DE group compared with Normal Control group. In D group, more glucose was consumed, as compared with DE group. Based on the PET/CT data, low levels of glucose metabolism may be an important factor in the process of encephalopathy induced by diabetes (Figure 1(d)).
3.3. Abnormally High Expression of IGF-1R Occurs in the Brain Tissue of Rats Suffering from Diabetic Encephalopathy. IGFIR was measured by immunohistochemistry assay in DE group and D group. As is shown in Figures 2(a) and 2(b), compared with Normal Control group, it was found a sharp increase of IGF-1R in DE group, but there was a decrease in the diabetic group. On the other hand, no difference of IGF$1 \mathrm{R}$ expression was seen among the Normal Control group, DE group and D group in Figures 2(a) and 2(b) using the same method. Abnormally high expression of IGF-1R has been found in the studies for the organizations rarely. This phenomenon was ever confusing to us, so we decided to 

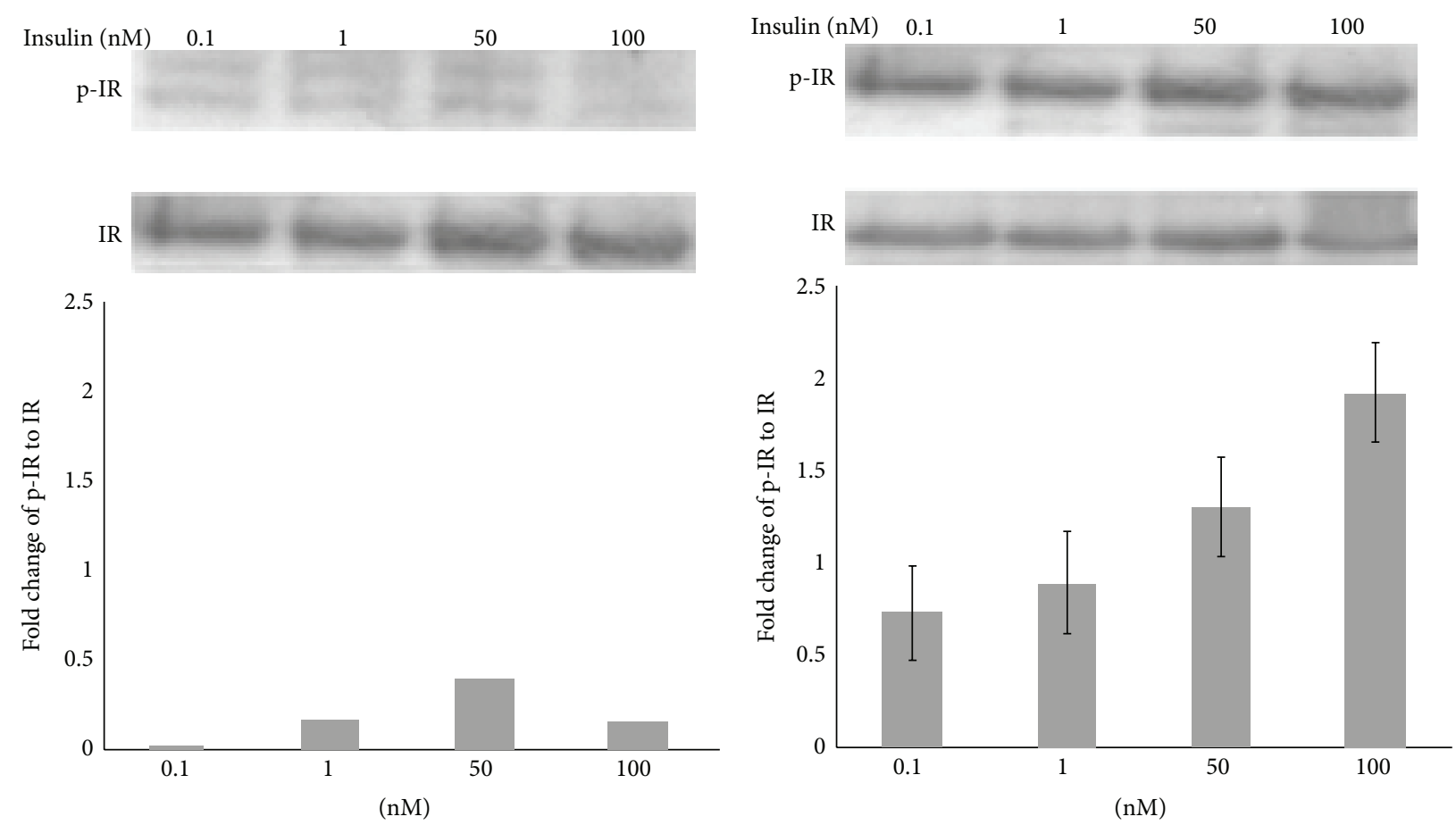

(a)

(b)

FIGURE 3: Selective insulin-induced phosphorylation of IRS-1 in $\Delta$ IGF-1R PC-12 cells (a, b).

construct the transformed PC12 cell that expressed IGF-1R lower than normal cells. Speculation confirmed earlier that low IGF-1R expression is good for the glucose metabolism of neurons cell.

3.4. The Defect of IGF-1R Significantly Improved the Ability of Glucose Consumption in PC12 Cells. It is known that A $\beta 25-35$ peptide has toxicity to affect the ability of glucose consumption of PC12 cell. At the resting state (no insulin), glucose consumption of PC12 $\triangle \mathrm{IGF}-1 \mathrm{R}$ cell and PC12 cell has no significant increase or decrease on the four time points $(P>$ 0.05).

In Figure 4(a), compared with Normal Control group, PC1 2 cells and $\triangle I G F-1 R-P C 12$ pretreated with $A \beta 25-35$, the amount of glucose that was consumed by these two cells was decreased; in particular, PC12 cells treated with A $\beta 25-35$ have shown the weakest glucose consumption capacity. Here it is important that $\triangle \mathrm{IGF}-1 \mathrm{R}-\mathrm{PC} 12$ cells consumed the glucose more than that of $\mathrm{PC} 12$ cell treated with $\mathrm{A} \beta 25-35$. The data suggest that the defect of IGF-1R significantly improved the ability of glucose consumption in PC12 cells but still did not completely reverse the damage caused by A $\beta 25-35$.

At the resting state (no insulin) both of cell groups have no significant increase or decrease $(P>0.05)$ of glucose consumption on the four time points. As is shown in Figure 4(c), compared with $\mathrm{PC} 12$ cells, in insulin-pretreated PC12 cells and $\triangle \mathrm{IGF}-1 \mathrm{R}-\mathrm{PC} 12$ cells incubated by A $\beta 25-35$, glucose uptake capacity was significantly improved by the defect of IGF-1R $(P<0.05)$, suggesting the defect of IGF-1R promotes mRNA level of Glut 4 and the uptaking of glucose significantly in the insulin-stimulated PC12 cells (Figures 2(c), 2(d), and 2(e)).

3.5. The knock-Down (IGF-1R neo $)$ Mice Treated with HFD/STZ Have Better Cognitive Abilities Than Those of Wild Mice. Due to operational difficulties in molecular biology, we have not been able to use the rat model with lower expression of IGF$1 \mathrm{R}$. The knock-down (IGF-1R ${ }^{\text {neo }}$ ) mice were made applying some similar methods which were reported [30].

Considering respiratory failure and exhibiting a more severe growth deficiency in lung, null IGF-1R ${ }^{-}$Mice have not been used as a model in the study. Using (PE) for 10 (for each treatment group) Histology of the overall digital analysis in hippocampus, compared to wild-type mice models, the knock-down (IGF-1R ${ }^{\text {neo }}$ ) mice were significantly reduced in the control group that was approximately $33 \%$. Due to insufficient accuracy of our PET-CT for animal, it cannot be used to detect levels of glucose metabolism in mice of the head; it is so regret in the study. Fortunately, the results of body weight, blood glucose, and cognitive abilities indicate the weight of knock-down IGF-1R ${ }^{\text {neo }}$ mice fed with high-fat high-sugar is lower than that of wild-type mice; this may be a positive tip that the IGF-1R ${ }^{\text {neo }}$ mice have a greater ability of glucose metabolism. More important is the knock-down (IGF-1R $\left.{ }^{\text {neo }}\right)$ mice blood glucose levels were significantly lower than the wild type, with statistical significance $(P<0.05)$, but still higher than the normal diet of knock-down (IGF-1R ${ }^{\text {neo }}$ ) mice $(P<0.01)$. As is shown in Tables 1 and 2 , Morris water maze tests revealed the most important experimental result; only 2 knock-down (IGF-1R ${ }^{\text {neo }}$ ) mice showed slight cognitive 

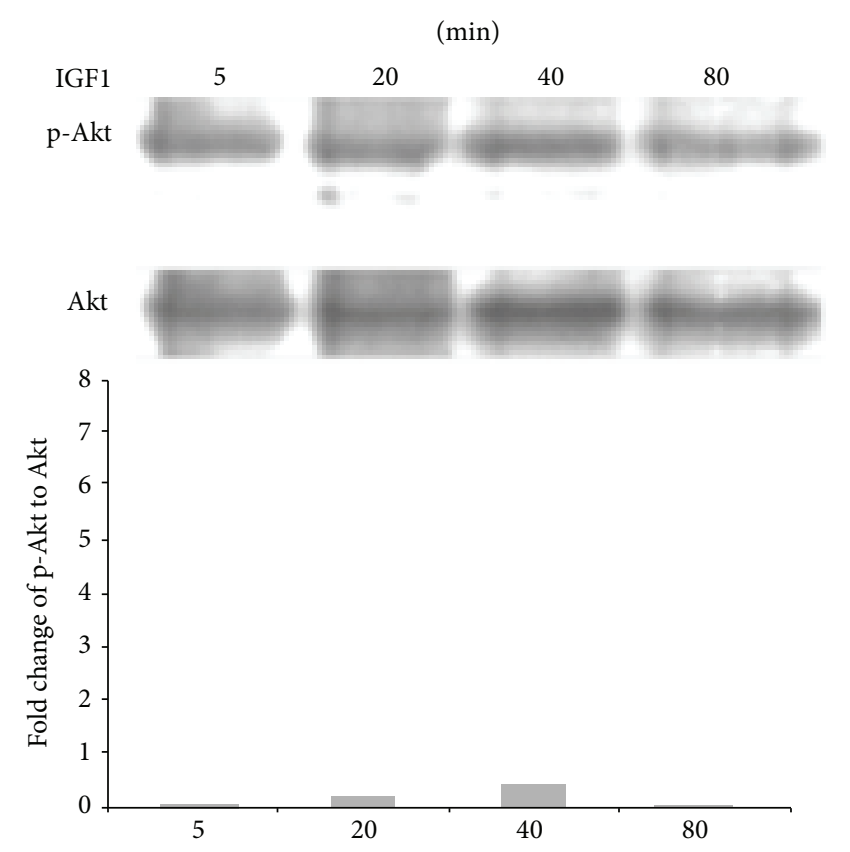

(a)

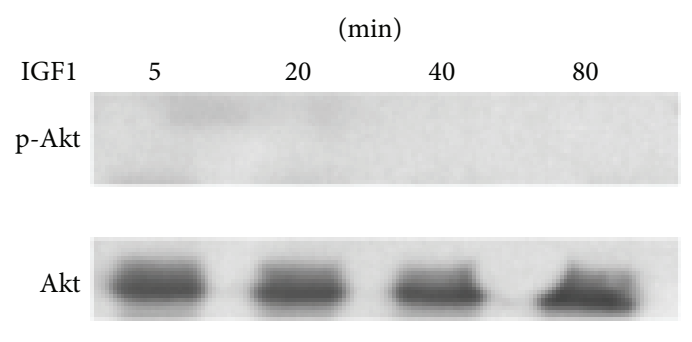

(b)
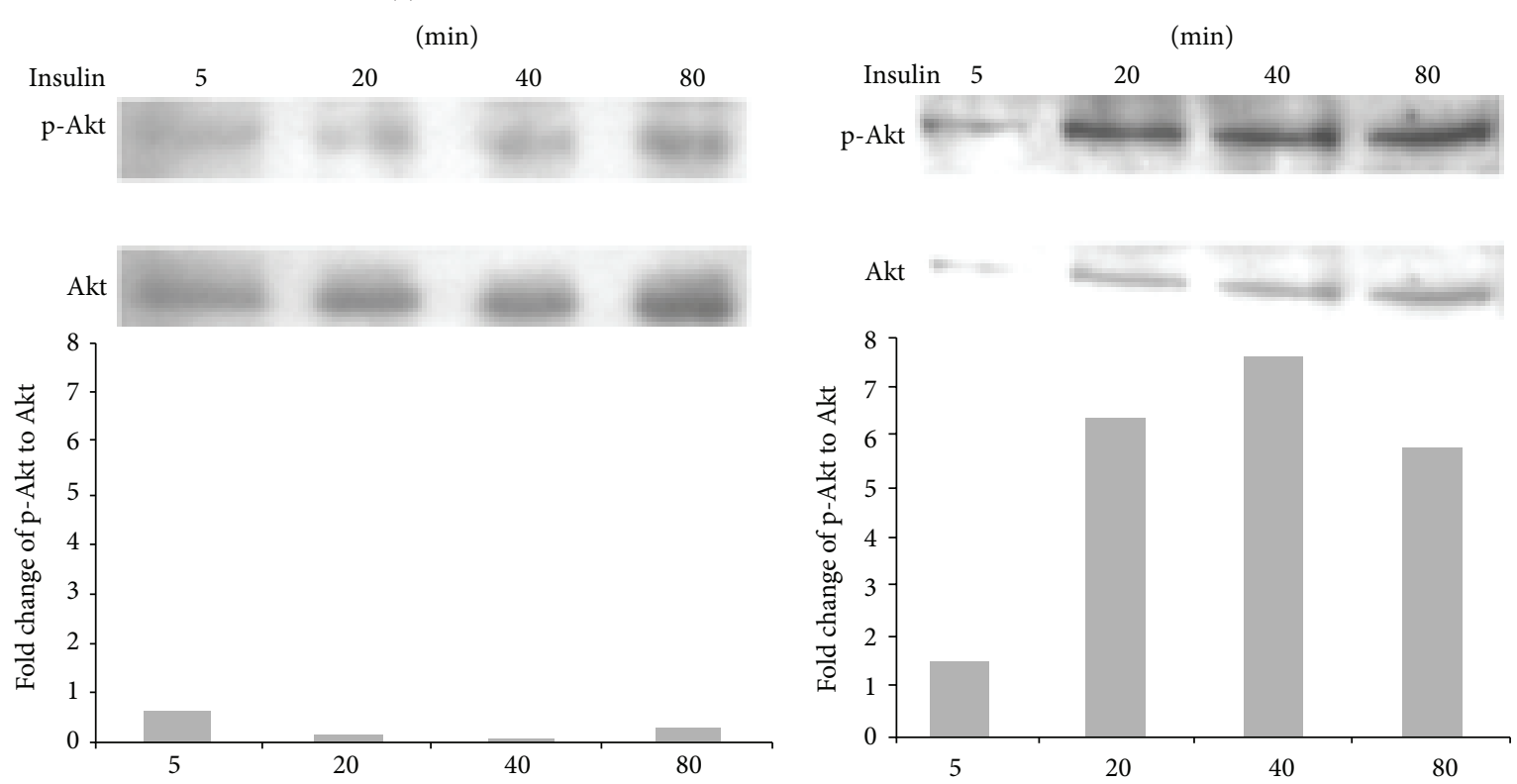

(c)

(d)

FIGURE 4: Loss of the IGF-1R enhances sensitivity to insulin-induced (a) and IGF1 (b) Akt phosphorylation.

barrier. However, 7 mice in wild-type mice fed with highsugar high-fat treatment group had three in a serious cognitive disorder. Until testing the latter $(25 \mathrm{w})$, the living state of all wild mice was not suitable for water Morris maze test, while no knock-down (IGF-1R ${ }^{\text {neo }}$ ) mice still have the athletic ability and cognitive ability.

In summary, the low expression of IGF-1R could be help to inhibit diabetic encephalopathy to some extent.

3.6. Loss of the IGF-1R Enhances Sensitivity to Insulin-Induced IR Phosphorylation. To investigate the effects of IGF-1R disruption on immediate IR signaling, we examined IR autophosphorylation in the cells. The $\Delta \mathrm{IGF}-1 \mathrm{R}$ and control cells were serum-starved and treated with insulin, lysed, and immunoprecipitated with the anti-IR- $\beta$ antibody. Western blot analysis with an anti-Tyr (P) antibody showed that insulin stimulated tyrosine phosphorylation of the insulin receptor in both $\triangle \mathrm{IGF}-1 \mathrm{R}$ and control cells (Figures 3(a) and $3(\mathrm{~b}))$. However, in the $\Delta \mathrm{IGF}-1 \mathrm{R}$ cells, IR was more responsive to insulin, leading to IR autophosphorylation at 100 -fold lower insulin concentrations $(0.1 \mathrm{nM})$ when compared with equivalent activation in control cells at the concentration of $10 \mathrm{nM}$. 
TABLE 1: Grade analysis of the pass-through time of mice in the water maze Automatic Control System test.

\begin{tabular}{lcc}
\hline$T_{p}-T / T_{p}$ & $\begin{array}{c}\text { Wild-mice HFD } \\
(n=18)\end{array}$ & $\begin{array}{c}\text { IGF-1R } \\
\operatorname{HFD}(n=18)\end{array}$ \\
\hline $0 \% \sim 20 \%$ & 11 & 16 \\
$20 \% \sim 30 \%$ & 3 & 2 \\
$30 \% \sim 40 \%$ & 3 & 0 \\
$>40 \%$ & 1 & 0 \\
\hline
\end{tabular}

$T_{p}=$ the pass-through time; $T=$ the middle time of negative control.

TABLE 2: The times of error in MS-2 water maze Automatic Control System test.

\begin{tabular}{lcccc}
\hline \multirow{2}{*}{ Groups } & \multicolumn{4}{c}{ Times of error } \\
& Day 1 & Day 2 & Day 3 & Day 4 \\
\hline $\begin{array}{l}\text { NS control } \\
\text { group }\end{array}$ & $9.12 \pm 8.01$ & $7.50 \pm 5.56$ & $5.43 \pm 4.42$ & $3.65 \pm 2.21$ \\
$\begin{array}{l}\text { Wild-mice } \\
\text { HFD }\end{array}$ & $15.08 \pm 5.13$ & $15.71 \pm 10.15$ & $12.13 \pm 5.70$ & $7.30 \pm 2.11$ \\
$\begin{array}{l}\text { IGF-1R } \\
\text { mice }\end{array}$ & $11.12 \pm 7.01$ & $8.50 \pm 4.11$ & $7.24 \pm 4.57^{*}$ & $5.88 \pm 2.46^{*}$ \\
${ }^{*} P<0.05 ; n=18$ mice per group. & & &
\end{tabular}

3.7. Loss of the IGF-1R Enhances Sensitivity to Insulin-Induced Akt Phosphorylation. Ligand binding to IR and IGF-1R activates Akt signaling pathways. As shown in Figure 4, IGF-1 acutely stimulated Akt (Figures 4(a) and 4(b), left panels) in control cells, whereas these effects were nearly abolished in $\triangle \mathrm{IGF}-1 \mathrm{R}$ cells. Interestingly, insulin treatment resulted in significantly greater induction of Akt phosphorylation in PC12- $\triangle$ IGF-1R cells compared with control cells. The enhanced insulin sensitivity in $\Delta \mathrm{IGF}-1 \mathrm{R}$ cells is opposite to that observed for growth hormone signaling where removal of the IGF-1R diminishes growth hormone induction of JAK/STAT phosphorylation.

\section{Discussion}

Diabetic encephalopathy is an unknown diabetes complication, characterized by electrophysiological, structural, neurochemical, and degenerative neuronal changes that lead to cognitive functioning limitations. Hence it is named as "type 3 diabetes"; the content of this title represents the most relevant risk factor for increased incidence of dementia, cognitive dysfunction, and consequently Alzheimer's disease.

As is known widely, insulin is an important anabolic hormone identified, since almost all of cell types are sensitive to this peptide [32]. More and More evidence proved that the hormone is widely located in the brain [32]. It plays a critical and central role in numerous actions in the brain, like neurotrophic, neuromodulatory, and neuroendocrine [3335]. Additionally, insulin runs in the CNS through binding to the receptors on cell membrane-insulin receptor (IR) and insulin growth factor-1 receptor (IGF-1R); they are so abundant throughout the whole brain, such as hypothalamus, hippocampus $[36,37]$. Once bound to the receptors, insulin triggers signaling cascades that include PI-3K and Akt pathways, which are the most relevant factors involved in learning and memory processes [38].

Insulin-like growth factor-1 receptor (IGF-1R) locates on the cell types in many human tissues [39]. Two peptide hormones called IGF-1 and IGF-2 both can activate it effectively. Their actions are mostly like insulin. Both of them have anabolic effects in adults-meaning that it can induce hypertrophy of brain and other target tissues. IGF-1R and other tyrosine kinase growth factor receptors signal through multiple pathways. In Figure 3, the results of Western blot showed that IR on $\triangle$ IGF-1R cells was more susceptible to insulin, so the pathways between IR and IGF-1R may cross and overlap; if one of them defects, the other will operate alternately. A key pathway is regulated by phosphatidylinositol-3 kinase (PI3K) and its downstream partner, the mammalian target of rapamycin. IGF-1 prosurvival action is mainly activated by the PI3K/Akt pathway [40, 41]. PI3K inhibitors or expression of an inactive Akt mutant can suppress the neuroprotective effects of IGF-1, supporting the hypothesis that the survival signal is mediated predominantly through this pathway. Furthermore, some inflammatory factors, such as tumor necrosis factor- (TNF-) alpha can also indirectly trigger the death of neurons by inhibiting essential components of the IGF-1 survival response, such as PI3K, further demonstrating the key role of the IGF-1/PI3K-Akt pathway in neuroprotection.

Activation of PI3K stimulates the phosphorylation of the survival kinase, Akt. Activated Akt can phosphorylate multiple downstream proteins related to cell survival. This is consistent with a recent study, which demonstrated that no regional or aging difference was observed in total Akt level, but activated Akt was significantly reduced in hippocampal CA1 region [42-45]. As shown in Figure 4, IGF-1 in $\triangle$ IGF$1 \mathrm{R}$ cell had no effects on $\Delta \mathrm{IGF}-1 \mathrm{R}$ cells. On the other hand, more insulin-sensitivity was identified in $\Delta$ IGF-1R cells than the cells in control. These results suggest that the decrease of p-Akt signaling is related to the vulnerability of CA1 neurons to stressor such as ischemia.

\section{Conclusion}

It is concluded that insulin exerts direct anabolic actions in neuron-like cells by activation of its cognate receptor and proves that IGF-1R plays an important role of in the pathogenesis of diabetic encephalopathy.

\section{Conflict of Interests}

The authors declare that they have no financial and personal relationships with other people or organizations that can inappropriately influence their work and there is no professional or other personal interest of any nature or kind in any product, service, and/or company that could be construed as influencing the position presented in, or the review of, the paper. 


\section{References}

[1] M. Baldassarre, F. A. Giannone, L. Napoli et al., "The endocannabinoid system in advanced liver cirrhosis: pathophysiological implication and future perspectives," Liver International, vol. 33, no. 9, pp. 1298-1308, 2013.

[2] Y.-W. Chen, V. Boyartchuk, and B. C. Lewis, "Differential roles of insulin-like growth factor receptor- and insulin receptormediated signaling in the phenotypes of hepatocellular carcinoma cells," Neoplasia, vol. 11, no. 9, pp. 835-845, 2009.

[3] Q. L. Cui and G. Almazan, "IGF-I-induced oligodendrocyte progenitor proliferation requires PI3K/Akt, MEK/ERK, and Src-like tyrosine kinases," Journal of Neurochemistry, vol. 100, no. 6, pp. 1480-1493, 2007.

[4] M. A. Daulatzai, "Early stages of pathogenesis in memory impairment during normal senescence and alzheimer's disease," Journal of Alzheimer's Disease, vol. 20, no. 2, pp. 355-367, 2010.

[5] M. L. De Paula, Q.-L. Cui, S. Hossain, J. Antel, and G. Almazan, "The PTEN inhibitor bisperoxovanadium enhances myelination by amplifying IGF-1 signaling in rat and human oligodendrocyte progenitors," GLIA, vol. 62, no. 1, pp. 64-77, 2014.

[6] A. M. Etgen, O. González-Flores, and B. J. Todd, "The role of insulin-like growth factor-I and growth factor-associated signal transduction pathways in estradiol and progesterone facilitation of female reproductive behaviors," Frontiers in Neuroendocrinology, vol. 27, no. 4, pp. 363-375, 2006.

[7] Y. F. Zhi, J. B. Prins, and T. H. Marwick, "Diabetic cardiomyopathy: evidence, mechanisms, and therapeutic implications," Endocrine Reviews, vol. 25, no. 4, pp. 543-567, 2004.

[8] S. Fernandez, A. M. Fernandez, C. Lopez-Lopez, and I. TorresAleman, "Emerging roles of insulin-like growth factor-I in the adult brain," Growth Hormone \& IGF Research, vol. 17, no. 2, pp. 89-95, 2007.

[9] A. Gozzi, V. Crestan, G. Turrini, M. Clemens, and A. Bifone, "Antagonism at serotonin 5-HT2A receptors modulates functional activity of frontohippocampal circuit," Psychopharmacology, vol. 209, no. 1, pp. 37-50, 2010.

[10] B. H. Harvey, "Is major depressive disorder a metabolic encephalopathy?", Human Psychopharmacology: Clinical and Experimental, vol. 23, no. 5, pp. 371-384, 2008.

[11] B. P. Head, J. N. Peart, M. Panneerselvam et al., "Loss of caveolin-1 accelerates neurodegeneration and aging," PLoS ONE, vol. 5, no. 12, Article ID el5697, 2010.

[12] A. Hematulin, D. Sagan, F. Eckardt-Schupp, and S. Moertl, "NBS1 is required for IGF-1 induced cellular proliferation through the Ras/Raf/MEK/ERK cascade," Cellular Signalling, vol. 20, no. 12, pp. 2276-2285, 2008.

[13] C. E. Hills, N. J. Brunskill, and P. E. Squires, "C-peptide as a therapeutic tool in diabetic nephropathy," American Journal of Nephrology, vol. 31, no. 5, pp. 389-397, 2010.

[14] S. Lim, J. Hong, C.-T. Liu et al., "Common variants in and near IRS1 and subclinical cardiovascular disease in the Framingham Heart Study," Atherosclerosis, vol. 229, no. 1, pp. 149-154, 2013.

[15] H. Meng, D. Zhang, and H. Yang, "Effects of amyloid precursor protein 17 peptide on the protection of diabetic encephalopathy and improvement of glycol metabolism in the diabetic rat," Journal of Diabetes Research, vol. 2013, Article ID 689841, 7 pages, 2013.

[16] M. A. Rogawski, "What is the rationale for new treatment strategies in Alzheimer's disease?” CNS Spectrums, vol. 9, no. 7, supplement 5, pp. 6-31, 2004.
[17] A. P. Ross, E. C. Bruggeman, A. W. Kasumu, J. G. Mielke, and M. B. Parent, "Non-alcoholic fatty liver disease impairs hippocampal-dependent memory in male rats," Physiology and Behavior, vol. 106, no. 2, pp. 133-141, 2012.

[18] B. A. Stoica, V. A. Movsesyan, P. M. Lea IV, and A. I. Faden, "Ceramide-induced neuronal apoptosis is associated with dephosphorylation of Akt, BAD, FKHR, GSK-3 $\beta$, and induction of the mitochondrial-dependent intrinsic caspase pathway," Molecular and Cellular Neuroscience, vol. 22, no. 3, pp. 365-382, 2003.

[19] M. J. Strong, "The syndromes of frontotemporal dysfunction in amyotrophic lateral sclerosis," Amyotrophic Lateral Sclerosis, vol. 9, no. 6, pp. 323-338, 2008.

[20] H.-S. Suh, M.-L. Zhao, L. Derico, N. Choi, and S. C. Lee, "Insulin-like growth factor 1 and 2 (IGF1, IGF2) expression in human microglia: Differential regulation by inflammatory mediators," Journal of Neuroinflammation, vol. 10, article 37, 2013.

[21] K. Thind and M. N. Sabbagh, "Pathological correlates of cognitive decline in Alzheimer's disease," Panminerva Medica, vol. 49, no. 4, pp. 191-195, 2007.

[22] J. Trojan, J.-F. Cloix, M.-Y. Ardourel, M. Chatel, and D. D. Anthony, "Insulin-like growth factor type I biology and targeting in malignant gliomas," Neuroscience, vol. 145, no. 3, pp. 795811, 2007.

[23] R. L. Tuttle, N. S. Gill, W. Pugh et al., "Regulation of pancreatic $\beta$-cell growth and survival by the serine/threonine protein kinase Akt1/PKB $\alpha$," Nature Medicine, vol. 7, no. 10, pp. 1133-1137, 2001.

[24] H. U. Ung, A. R. Moehlig, R. A. Kudla et al., "Proton-bound dimers of 1-methylcytosine and its derivatives: vibrational and NMR spectroscopy," Physical Chemistry Chemical Physics, vol. 15, no. 43, pp. 19001-19012, 2013.

[25] X. Vafopoulou and C. G. H. Steel, "Insulin-like and testis ecdysiotropin neuropeptides are regulated by the circadian timing system in the brain during larval-adult development in the insect Rhodnius prolixus (Hemiptera)," General and Comparative Endocrinology, vol. 179, no. 2, pp. 277-288, 2012.

[26] A. I. Vinik, T. Erbas, K. S. Stansberry, and G. L. Pittenger, "Small fiber neuropathy and neurovascular disturbances in diabetes mellitus," Experimental and Clinical Endocrinology and Diabetes, vol. 109, no. 2, pp. S451-S473, 2001.

[27] A. Von Gunten, K. Ebbing, A. Imhof, P. Giannakopoulos, and E. Kövari, "Brain aging in the oldest-old," Current Gerontology and Geriatrics Research, vol. 2010, Article ID 358531, 10 pages, 2010.

[28] X. K. Wang, M. L. Michaelis, and E. K. Michaelis, "Functional genomics of brain aging and Alzheimer's disease: focus on selective neuronal vulnerability," Current Genomics, vol. 11, no. 8, pp. 618-633, 2010.

[29] B. K. Wicker, H. P. Hutchens, Q. Wu, A. T. Yeh, and J. D. Humphrey, "Normal basilar artery structure and biaxial mechanical behaviour," Computer Methods in Biomechanics and Biomedical Engineering, vol. 11, no. 5, pp. 539-551, 2008.

[30] R. Epaud, F. Aubey, J. Xu et al., "Knockout of insulin-like growth factor-1 receptor impairs distal lung morphogenesis," PLoS ONE, vol. 7, no. 11, Article ID e48071, 2012.

[31] S. Jiang, P. Du, L. An, G. Yuan, and Z. Sun, "Anti-diabetic effect of Coptis Chinensis polysaccharide in high-fat diet with STZinduced diabetic mice," International Journal of Biological Macromolecules, vol. 55, pp. 118-122, 2013. 
[32] A. A. F. Sima, W. Zhang, C. W. Kreipke, J. A. Rafols, and W. H. Hoffman, "Inflammation in diabetic encephalopathy is prevented by C-peptide," Review of Diabetic Studies, vol. 6, no. 1, pp. 37-42, 2009.

[33] S. M. de la Monte, "Insulin resistance and Alzheimer's disease," BMB Reports, vol. 42, no. 8, pp. 475-481, 2009.

[34] J. Havrankova, J. Roth, and M. Brownstein, "Insulin receptors are widely distributed in the central nervous system of the rat," Nature, vol. 272, no. 5656, pp. 827-829, 1978.

[35] L. Plum, M. Schubert, and J. C. Brüning, "The role of insulin receptor signaling in the brain," Trends in Endocrinology and Metabolism, vol. 16, no. 2, pp. 59-65, 2005.

[36] L. Gasparini and H. Xu, "Potential roles of insulin and IGF-1 in Alzheimer's disease," Trends in Neurosciences, vol. 26, no. 8, pp. 404-406, 2003.

[37] A. Wada, H. Yokoo, T. Yanagita, and H. Kobayashi, "New twist on neuronal insulin receptor signaling in health, disease, and therapeutics," Journal of Pharmacological Sciences, vol. 99, no. 2, pp. 128-143, 2005.

[38] C. C. Huang, C. C. Lee, and K. S. Hsu, "The role of insulin receptor signaling in synaptic plasticity and cognitive function," Chang Gung Medical Journal, vol. 33, no. 2, pp. 115-125, 2010.

[39] A. Gallardo, E. Lerma, D. Escuin et al., "Increased signalling of EGFR and IGF-1R, and deregulation of PTEN/PI3K/Akt pathway are related with trastuzumab resistance in HER2 breast carcinomas," British Journal of Cancer, vol. 106, no. 8, pp. 13671373, 2012.

[40] T. R. Kim, E. W. Cho, S. G. Paik, and I. G. Kim, "Hypoxiainduced SM22 $\alpha$ in A549 cells activates the IGF-1R/PI3K/Akt pathway, conferring cellular resistance against chemo- and radiation therapy," FEBS Letters, vol. 586, no. 4, pp. 303-309, 2012.

[41] M. Goto, A. Iwase, T. Harata et al., "IGF1-induced AKT phosphorylation and cell proliferation are suppressed with the increase in PTEN during luteinization inhuman granulosa cells," Reproduction, vol. 137, no. 5, pp. 835-842, 2009.

[42] M. de Butte-Smith, R. S. Zukin, and A. M. Etgen, "Effects of global ischemia and estradiol pretreatment on phosphorylation of Akt, CREB and STAT3 in hippocampal CAl of young and middle-aged female rats," Brain Research, vol. 1471, pp. 118-128, 2012.

[43] M. Racaniello, A. Cardinale, C. Mollinari et al., "Phosphorylation changes of CaMKII, ERK1/2, PKB/ Akt kinases and CREB activation during early long-term potentiation at Schaffer collateral-CA1 mouse hippocampal synapses," Neurochemical Research, vol. 35, no. 2, pp. 239-246, 2010.

[44] T. C. Jackson, A. Rani, A. Kumar, and T. C. Foster, "Regional hippocampal differences in AKT survival signaling across the lifespan: implications for CA1 vulnerability with aging," Cell Death and Differentiation, vol. 16, no. 3, pp. 439-448, 2009.

[45] V. Znamensky, K. T. Akama, B. S. McEwen, and T. A. Milner, "Estrogen levels regulate the subcellular distribution of phosphorylated Akt in hippocampal CA1 dendrites," The Journal of Neuroscience, vol. 23, no. 6, pp. 2340-2347, 2003. 


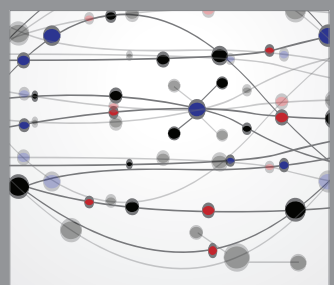

The Scientific World Journal
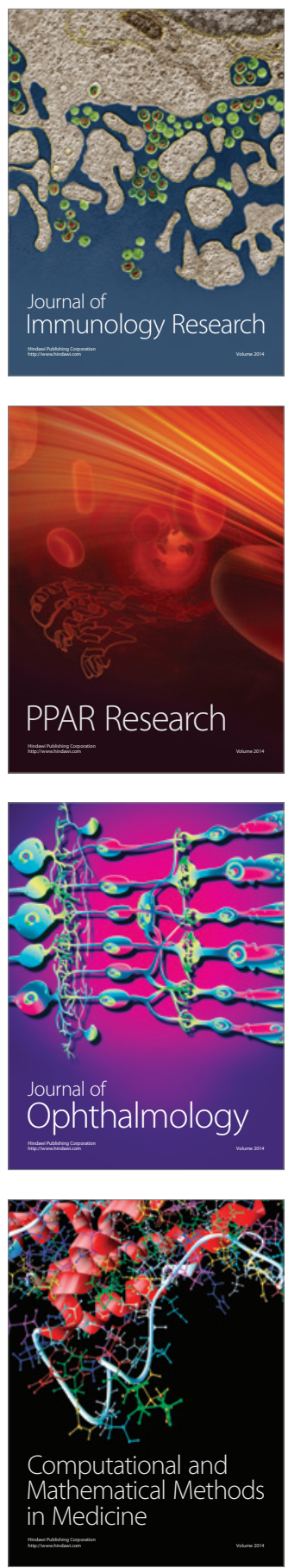

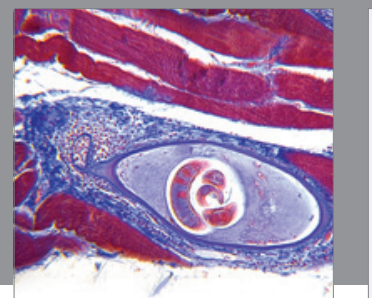

Gastroenterology

Research and Practice
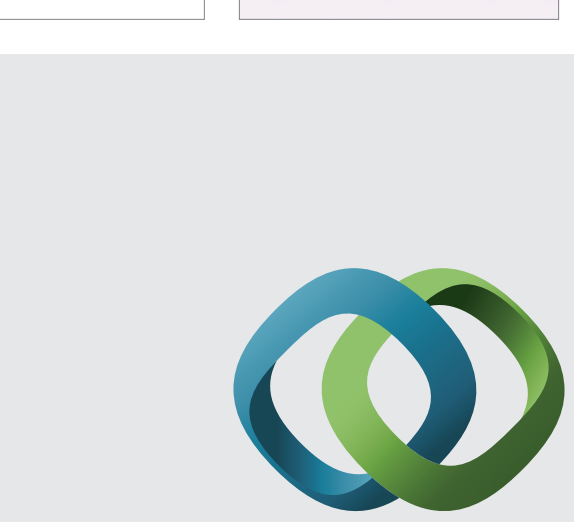

\section{Hindawi}

Submit your manuscripts at

http://www.hindawi.com
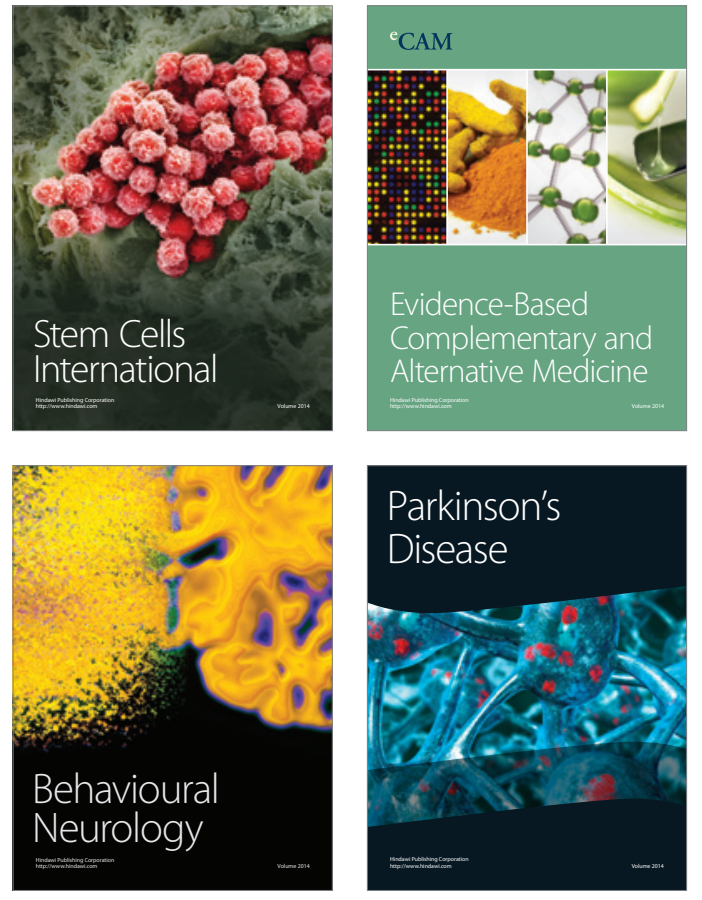
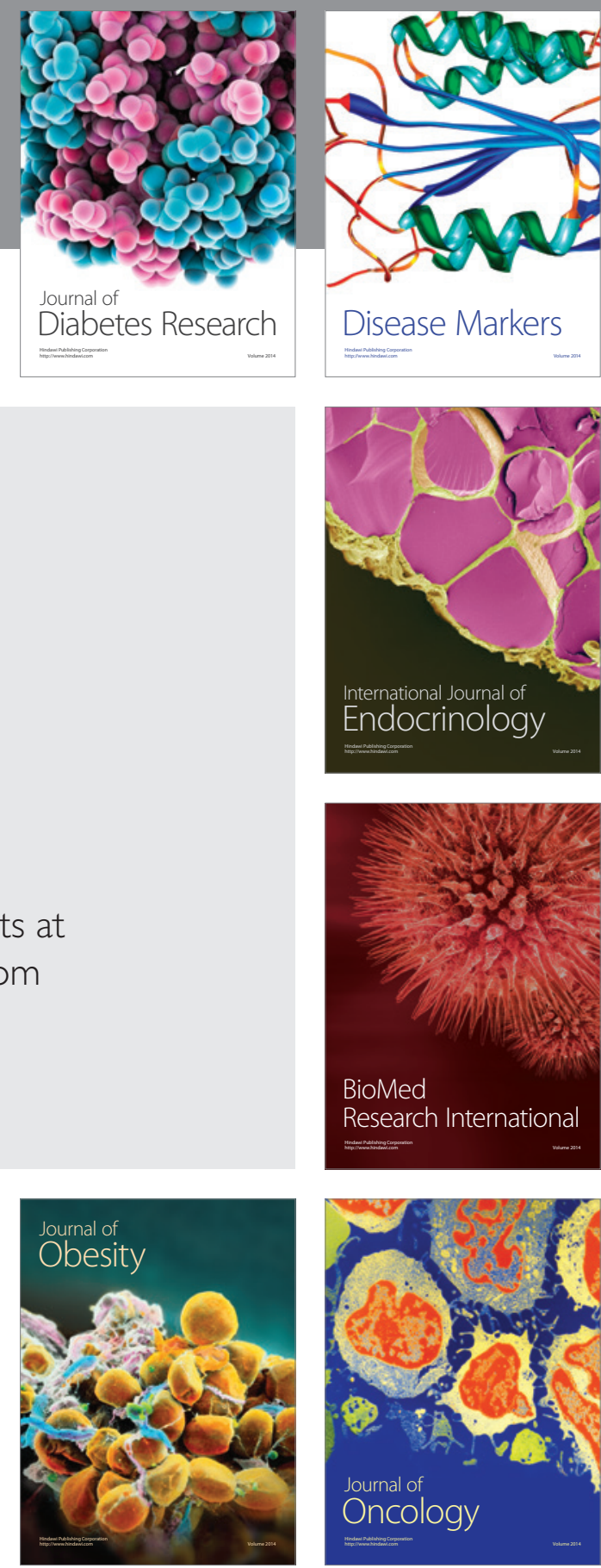

Disease Markers
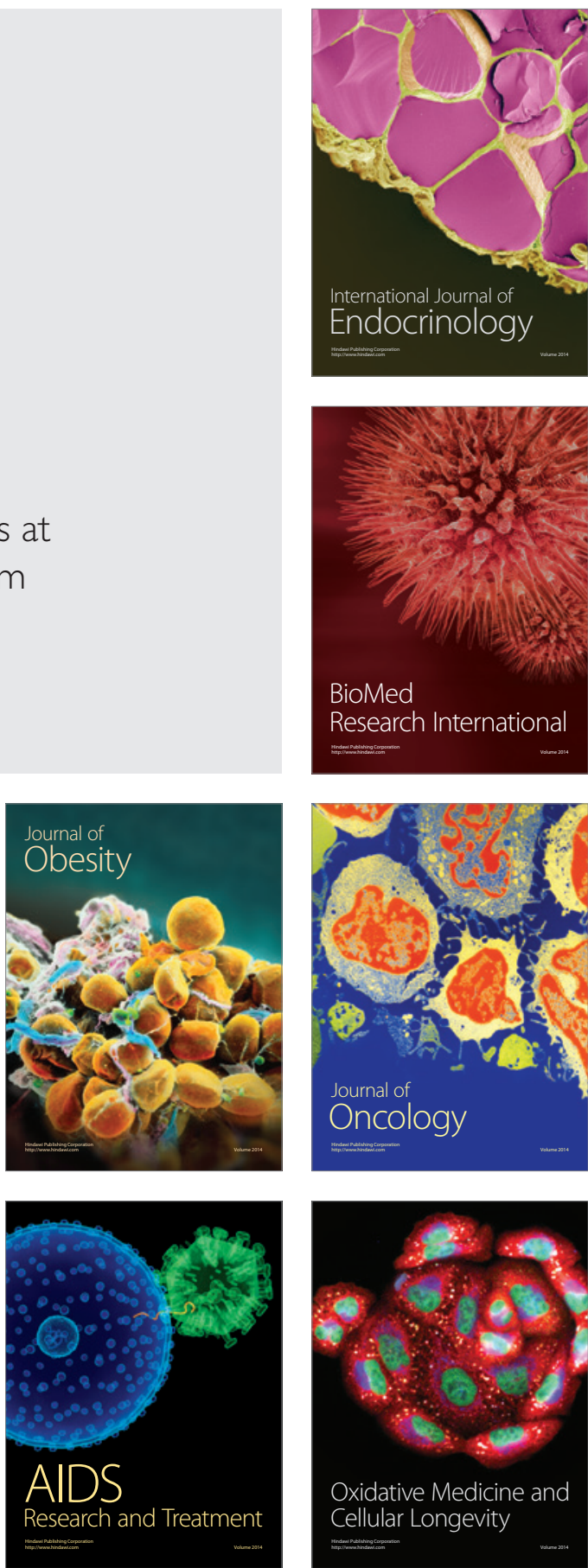